\title{
Adela Cortina, Aporofobia, el rechazo al pobre: un desafío para la democracia, Barcelona, Paidós, 2017, 196 pp.
}

$\mathrm{E}$ n su último libro, la filósofa Adela Cortina expone de una manera muy pedagógica y adaptada para un amplio público, una reflexión crítica sobre el término que ella misma acuñó. Aporofobia, el rechazo al pobre tiene la virtud, entre otras, de incluir ya en el título la explicación del mismo término. No se trata solamente de un estudio y reflexión crítica sobre el estado de la pobreza actual, sino que es además la descripción de una realidad social: el fenómeno de animadversión hacia aquellos que no pueden aportar nada en el término "pobre" del título se incluye, entre otros, a los refugiados políticos, a los mendigos, a los inmigrantes pobres, y a todos aquellos que esta sociedad de consumo y bienestar invisibiliza. Es decir, no solo se habla de pobreza económica, sino de la imposibilidad de llevar a cabo los propios planes de vida y mantener una vida digna. El subtítulo de la obra, un desafío para la democracia, nos da a entender su tesis principal: una sociedad justa para el siglo XXI debería exigir moral, política y legalmente acabar con el rechazo y la marginación de estos colectivos, y debería hacerlo a través del progreso y educación moral de los individuos y las instituciones en primer término.

El término "aporofobia" hace referencia a la lacra sin nombre de la que Cortina nos habla en el primer capítulo. Este es un concepto publicado por pri- mera vez en el año 1995 en el diario $A B C$ cultural, con el que la autora se refiere al rechazo al pobre -etimológicamente áporos, "pobre", y fobia, "rechazo o miedo"- como una realidad social contundente. Esta realidad transmite que más allá de la etnia, la raza, o el hecho de ser extranjero, como causas de odio o rechazo más habituales de ciertos colectivos, se trata de una cuestión de pobreza. Por ello, era urgente que la RAE incorporara el término, más allá de las causas comunes que se suelen utilizar, como el uso social de una palabra. En efecto, "aporofobia” no era un término que se usara masivamente, pero sí un término necesario para identificar un mal existente.

Este mal existente es inherente a los delitos de odio, tal y como se expone en el capítulo segundo. Estos delitos se pueden dividir en incidentes o discursos de odio. Siguiendo a autores como André Glucksmann, la autora enumera tres características de estos delitos: no se suelen cometer contra una persona determinada sino indeterminada, por el hecho de pertenecer a un colectivo con una serie de características; estigmatizan y denigran a un colectivo determinado, atribuyéndole actos perjudiciales para la sociedad; se realizan siempre contra minorías vulnerables, y quienes los realizan están convencidos de su superioridad. Para combatirlos, junto con el Estado y el Derecho, se hace necesaria la acción de una sociedad civil comprometida 
con erradicar la desigualdad y cultivar la dignidad.

En el capítulo tercero se incide en los discursos de odio como principal obstáculo para la convivencia democrática. Estos discursos son cada vez más dificiles de controlar debido a las redes sociales y el ciberespacio. Tras abordar la disyuntiva entre el "discurso de odio"-que no debería ser protegido por la libertad de expresión- y el "discurso impopular y ofensivo"-a menudo protegido por esta- la autora apuesta no solo por las medidas jurídicas sino por el carácter ético de una democracia para prevenir el primero. Incluso, llega a afirmar que el propio término "discurso del odio" es en sí una contradicción. Es un error hablar de "discurso" cuando el odio es monológico. Quien lo pronuncia no considera al otro como un interlocutor válido, niega al oyente su capacidad de interlocución y de réplica. Es una relación de asimetría y de desigualdad radical.

Precisamente, otra contradicción se señala en el capítulo cuarto: aquella existente entre lo que las instituciones económicas y políticas legitiman moralmente, y lo que las personas terminan haciendo. Tras repasar mínimamente los niveles de desarrollo ontogenético de la conciencia moral realizados por Lawrence Kohlberg, seguido por la teoría de la evolución social de Jürgen Habermas, la autora explica el gran abismo que existe entre la ética que legitiman las instituciones y el juicio y la acción de sus ciudadanos. Es decir, mientras que se propugna un modelo de ciudadanía social en el que los ciudadanos ven protegidos sus derechos y en la que se predica la necesidad de construir un mundo sin excluidos, la aporofobia sigue siendo una realidad. Mientras que en la historia de la filosofía numerosos autores han aludido a un "mal radical" del ser humano, ha sido posible, en parte gracias a la entrada en vigor de las neurociencias, estudiar esa especie de mal radical desde el punto de vista neurobiológico.

Para intentar explicar las bases neurobiológicas de la aporofobia, la autora remite primero a las de la xenofobia. Algunas teorías en neuroética han señalado que los seres humanos somos xenófobos empáticos por naturaleza. Es decir, poseemos simpatía selectiva, una tendencia biológica y evolutiva a cooperar con el grupo y a considerar como extraños a aquellos que provienen de fuera. Su origen posiblemente se encuentre en las emociones sociales: aquellas emociones que conducían al prejuicio racial o cultural servían desde el punto de vista evolutivo para detectar las amenazas y los peligros hacia el propio grupo. Sin embargo, a pesar de que nuestro cerebro cuenta con unos códigos de conducta seleccionados evolutivamente, existen otras conductas que no pueden explicarse desde esta perspectiva, como el altruismo biológico. Esto evidencia que el ser humano no solo está programado neurobiológicamente para el prejuicio, el rechazo, o la exclusión, sino también para la cooperación y la solidaridad. Tomando como referencia la epigénesis proactiva de Katinka Evers, la evolución del cerebro no solo es biológica sino cultural, pues el aprendizaje y la experiencia se mezclan con la acción de los genes. Crear unas instituciones y organizaciones justas y que reconozcan a los "sin poder" será clave para que las acciones de las personas también se encaminen en este sentido.

Una vez tratadas las bases cerebrales y sociales de la aporofobia, y cómo 
estas pueden ser modificadas a través no solo de la educación sino también de las instituciones que fomenten la dignidad humana, en el capítulo quinto la autora trata la relación que existe entre la conciencia y la reputación en la acción moral. Los estudios neurobiológicos de la conciencia moral apuntan a que, evolutivamente, está muy ligada al altruismo moral. Al parecer, la vergüenza y la reputación se convirtieron en indispensables para la supervivencia del individuo y del propio grupo. Sin embargo, y bajo una perspectiva nietzscheana, parece que nos las arreglamos mejor con nuestra conciencia que con la mala reputación. Por tanto, y aplicado al contexto que nos ocupa, nos vemos obligados a desarrollar conductas más prosociales cuando nos sentimos observados y peligra nuestra reputación. Pero ¿no existe entonces ningún momento de obligación incondicionado? Desde el punto de vista kantiano, la obligación interna está en la base de la conciencia moral y de los deberes hacia uno mismo y hacia los demás. Son comunes para esta justificación las alusiones -en este y en otros capítulos de la obra- al vínculo incondicionado entre los seres humanos como base de su reconocimiento recíproco, algo que la autora ya trató en su Ética de la razón cordial. Este vínculo cordial se toma como la primera base para acabar con la aporofobia.

Sin embargo, además de una base teórica que nos remita a un momento incondicionado para la acción moral, necesitamos también de la educación. Precisamente, en el capítulo sexto se aborda la disyuntiva entre la educación y la intervención neurocientífica sobre la motivación moral. Ciertamente, la biomejora es un tema muy actual de la bioética y la neuroética. La capaci- dad de intervenir en la potenciación de ciertas capacidades, como la memoria y el razonamiento, nos ha hecho cuestionarnos si tal intervención es aceptable y justa. Tras exponer las dos posiciones enfrentadas a este respecto, "bioconservadores" y "transhumanistas", la autora se centra en las posibilidades de mejora en el ámbito moral. Algo que, para autores como Thomas Douglas, no sería un problema, mientras que para autores como Julian Savulescu e Ingmar Persson sería un imperativo. El problema es cómo realizar esa mejora e intentar conjugar los bienes prudenciales con los bienes morales. Es evidente que la evolución de nuestras disposiciones biológicas no ha coincidido con el progreso moral en el nivel cultural. Más allá de apostar por una eugenesia liberal o autoritaria, hay que hacerlo por la educación moral, especialmente en los más jóvenes, como primer paso.

En el capítulo séptimo se abordan las desigualdades desde un análisis histórico y filosófico. En opinión de Cortina, cuando hablamos de pobreza es preciso aclarar cuatro cuestiones: (1) qué es ser pobre desde el punto de vista económico; (2) si la pobreza es evitable o por el contrario hay que acostumbrarse a ella; (3) si las condiciones de salida equitativas son un derecho de las personas o un cálculo de utilidades; (4) y si se trata de eliminar la pobreza material o de reducir las desigualdades económicas solamente.

En cuanto a la primera pregunta, parece muy adecuada la definición de Amartya Sen, quien desde el enfoque de capacidades dice que ser pobre es la incapacidad de poder llevar a cabo los planes de vida y la carencia de las capacidades básicas necesarias. Con respecto a la segunda pregunta, no fue hasta la 
segunda Ilustración (años 60 y 70 del siglo $\mathrm{XX}$ ) cuando la pobreza no se ve como algo inevitable, sino como algo que debe eliminarse y, además, hacerlo es en un deber del Estado. Es en ese momento cuando se extiende la convicción de que la pobreza es una coacción a la libertad de las personas y, consecuentemente, es inaceptable. En cuanto a la tercera pregunta, muchas políticas antipobreza han hecho uso de "la trampa de la pobreza", es decir, que las personas tengan lo suficiente para sobrevivir, pero no para salir de la pobreza. Es decir, no solo se trata de proteger el régimen político y la estabilidad de una sociedad, sino también promocionar a las personas pobres para que puedan salir de la pobreza. La reducción de las desigualdades es clave como forma de erradicar la pobreza, además de ser uno de los objetivos del milenio.

Por último, en el capítulo octavo, se aborda el tema de la hospitalidad como una de las posibles medidas contra la aporofobia. Hospitalidad entendida como una virtud, por sus raíces históricas y, especialmente, a partir de la tradición kantiana. Pero también complementada con la tradición de autores como Emmanuel Lévinas o Jacques Derrida en cuanto a la apertura al otro como característica básica del ser humano. Es decir, hospitalidad universal para una sociedad cosmopolita, como exigencia ética in- condicionada que brota del reconocimiento del respeto y la dignidad.

En definitiva, Aporofobia, el rechazo al pobre: un desafío para la democracia supone una visión fresca y a la vez preocupada por un problema social que ha estado vigente desde siempre, pero que ahora por fin tiene un nombre propio. Adela Cortina, quien ha mantenido una fecunda y extensa carrera académica y comprometida con la ética a nivel teórico y práctico, aborda desde una perspectiva interdisciplinar a través de estudios políticos, sociales, filosóficos y también neurocientíficos este problema, proponiendo horizontes de sentido, dificiles pero realistas. ${ }^{1}$

\section{DANIEL PALLARÉS-DOMÍNGUEZ Universitat Jaume I de Castellón}

${ }^{1}$ Este trabajo se inserta dentro de los objetivos del proyecto de la subvención para la contratación de personal investigador en fase posdoctoral [APOSTD/2017/003], concedida por la Consellería de Educación, Cultura y Deporte de la Generalitat Valenciana, y el Fondo Social Europeo. Además, esta contribución se enmarca en los objetivos concretos del proyecto de investigación de Ministerio de Economía y Competitividad titulado: "Neuroeducación moral para las éticas aplicadas" [FFI2016-76753-C2-2-P]. 